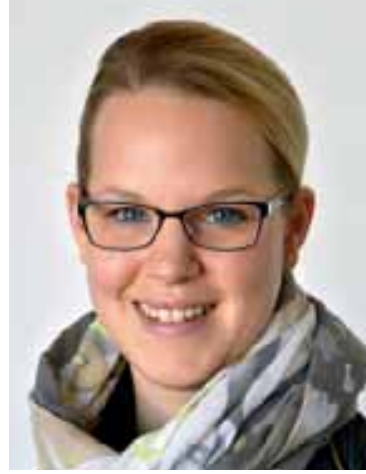

Kathrin Hage

Physiotherapeutin und Redakteurin

Editorial

kathrin.hage@thieme.de

\section{Kneifen ist nicht}

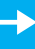

Wie ich meinen ersten Patienten mit Amputation behandelt habe, war haarsträubend. Er kam wegen Schulter-Nacken-Beschwerden zur Massage, die Oberarmamputation spielte an sich keine Rolle mehr. Keine Stumpfpflege, kein Wickeln. Doch es wäre angebracht gewesen, den amputierten Arm in die Funktionsmassage einzubinden. Allerdings konnte ich den Stumpf partout nicht ansehen - und schon gar nicht anfassen. Ich schämte mich furchtbar und hoffte inständig, nach den sechs Behandlungen nicht so schnell wieder mit Amputationen konfrontiert zu sein.

Ein Praktikum später, Reha-Klinik, M ontag früh. Ich sollte eine neue Patientin übernehmen. Die ältere Dame erwartete mich in ihrem Zimmer mit verweinten Augen. „Alle sagen, dass ich ins Pflegeheim muss. Kann ich wirklich nie mehr nach Hause?“, fragte sie mich und schlug die Bettdecke zurück. Oberschenkelamputation. Und nicht nur das. Die Dame hatte seit ihrem 20. Lebensjahr Rheumatoide Arthritis. Mit herkömmlichen Gehhilfen werden wir nicht weit kommen, schoss es mir durch den Kopf. Die Hände würden nie ihr Gewicht tragen oder die Griffe umfassen können. Aber das war ohnehin fünf Schritte zu weit gedacht. Wir standen ganz am Anfang. Erst einmal hieß es: Narbenpflege und in Kornähren wickeln, wovon ich keine Ahnung hatte. Aber zusammen mit meiner Patientin arbeitete ich mich in die Welt der Wickeltechniken, Prothesen und Liner ein. Denn schon in den ersten Minuten war klar: Kneifen ist nicht. Dieses Mal kann ich den Stumpf nicht einfach ignorieren. Die Frau baut auf mich, sie will wieder in die eigenen vier Wände. Und nach sieben Wochen waren wir so weit. Sie konnte heim.

Was für meine Patientin die Rückkehr in die eigene Wohnung war, war für Kalle Hüser (ab Seite 30) das Skateboard- und Rollschuhfahren. Mit zehn Jahren bekam er wegen eines Osteosarkoms am Femur eine Umkehrplastik nach Borggreve, wobei sein gesunder Unterschenkel um 180 Grad gedreht an das verkürzte Bein geplattet wurde. Fünf Jahre später stand er wieder auf dem Skateboard und den Rollschuhen. Ziele und der eiserne Wille, sie zu erreichen, bringen eben einiges ins Rollen ... sogar bei einer Therapeutin mit anfänglichen Berührungsängsten.

Herzlichst, Ihre

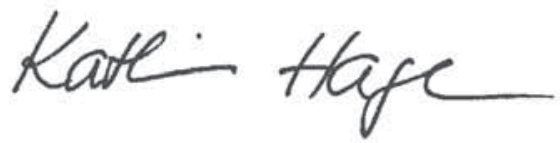

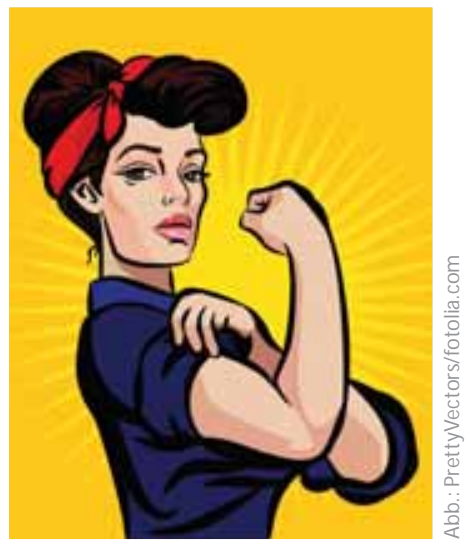

Als Superwoman oder -man fühlt man sich als Berufseinsteiger selten. Zu viele neue, teils heikle Situationen gilt es zu meistern. Sich vor innen zu drücken, geht nicht. 